\title{
The Social Marginalization of People Living with a Mentally Ill Label-Family, Friends, and Work
}

\author{
Kateřina Maloušková \\ Palacký University Olomouc, Czech Republic \\ Martin Fafejta \\ Palacký University Olomouc, Czech Republic
}

DOI: https://doi.org/10.18778/1733-8077.17.3.04

Keywords:

Mental Illness;

Labeling; Impairment;

Disability; Organized

Deviant Group;

Deviant Career;

Family; Friends;

Employment;

Marginalization;

Psychiatry

\begin{abstract}
This paper is based on qualitative research among people diagnosed with a mental illness who voluntarily attend a mental health center. Such individuals are given a degrading "mentally ill" label, which transforms them into a "new" person. This study showed that-due to their label-research participants are often socially marginalized-not only in the public but also in the private sphere. As members of an "organized deviant group" (the mental health center), they follow a "deviant career" and find a job outside the regular job market. Their marginalization is not only caused by their health problems (by their impairment), but they are also disabled through social reactions to these problems. Psychiatry based on the biological model of the disease cannot, therefore, help them without the cooperation of social science approaches dealing with social marginalization.
\end{abstract}

Kateřina Maloušková (née Karmazínová) is a graduate of Palacký University Olomouc, Czech Republic, with a Master's degree in Sociology and Czech Philology. In her Master's thesis, she focused on the labeling of mental illness.

email address: karmazinova.katerina@gmail.com
Martin Fafejta is an Assistant Professor at the Department of Sociology, Andragogy, and Cultural Anthropology, Palacký University Olomouc, Czech Republic. His research focuses on minorities, deviation, and the discursive construction of identity.

email address: martin.fafejta@upol.cz 


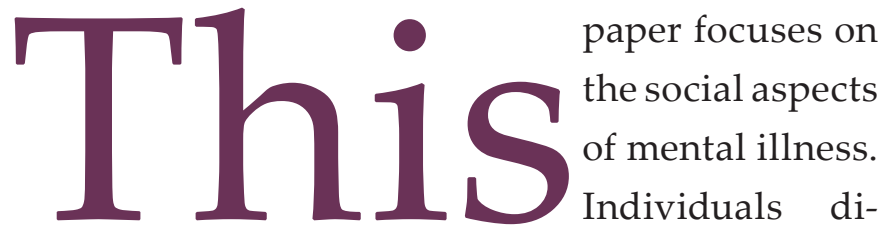

agnosed with a mental illness are given a degrading label by the majority, which transforms individual medical symptoms into the overall identity of the person. The text shows how this label may lead to the exclusion of the labeled person from the majority. Therefore, their marginalization is caused not only by mental illness but also by social reactions to individuals with mental illness. For this reason, the article further argues that psychiatric approaches based on pharmacological treatment, understanding mental illness as a purely biological matter, cannot suffice to integrate an individual into society. Unless society's attitudes (stereotypes and prejudices) towards individuals with mental illness change, these individuals will be socially marginalized despite advances in medical diagnosis and development in pharmacy.

\section{Research Design}

The research was based on a qualitative study among individuals diagnosed with mental illness voluntarily attending a client center for people with mental illness. One of the researchers attended this center for one month. For the first time, the researcher visited the center as part of a regular monthly informative meeting for clients, which brought together about twenty people. During this meeting, the research project was presented, and four clients responded positively to the call to participate. The rest of the participants were recruited through snowball sampling wherein the original informants led the researchers to other members of the target group (i.e., clients of the center). This is how a sample of a temporary population with relative existence was obtained- this temporality and relativity are given by their dependence on the existence of the center where the research participants meet and engage in joint activities. This association formed a social group with shared values, norms, and goals. At the same time, these individuals share the same label and similar experiences resulting from the label (Becker 1966).

A total of 13 persons participated in the study, men and women aged 35 to 68 years. These interviewees have varied diagnoses, which were not the focus of the research as the participants themselves stated that their diagnoses had changed several times in their lifetime. Semi-standardized interviews were used to gain insight into what it is like to live being labeled "mentally ill" and how the label affects the social life of those concerned. Non-participatory observation of the center's activities showed that the clients were used to talking in detail mostly about their mental health conditions, so the interviews were conducted to keep clients focused on their social life. The "comprehensive interview" technique by Kaufmann (1996) was employed. Kaufmann's approach is based on grounded theory and aims to disrupt the hierarchy between the researcher and the research participant, more closely resembling a conversation between two equal partners. Informed consent was signed with each participant before the interview, and all data were anonymized.

The researchers were particularly interested in whether the clients of the center felt discriminated against in certain social situations, and whether they felt the label affected their relationships with other people and job opportunities. The paper will focus primarily on three categories: family and partner relationships; relationships with friends and neighbors; and work and employment. 


\section{Theoretical Framework}

\section{Impairment and Disability}

In the article, mental illness is seen through the concept of disability studies distinguishing between impairment and disability. While impairment arises from specific physical or mental conditions, disability is socially or culturally imposed on top of the impairment. In the declaration of the Union of the Physically Impaired Against Segregation (UPIAS 1976:3), disability is understood not as a personal fact but a social one-it is a label that "unnecessarily isolates and excludes a person from full participation in society." Disabled persons suffer, for example, from work segregation, and they have lower incomes and higher unemployment than the majority. "Disability is, therefore, a particular form of social oppression" (UPIAS 1976:14).

This concept originated as a critique of the "medical model" of disability. The medical model sees disability purely as an individual problem and considers the isolation of people with impairment from the majority to be due to their impairment, and the only way to treat their problems is through medical tools. The sociocultural model of disability, which theoretically elaborates and specifies the original statements of the Union of the Physically Impaired Against Segregation, points out that "it is not impairments per se which disable, but societal practices of 'disablement' which result in disability" (Waldschmidt 2017:21). For example, most of the words referring to mental problems in everyday speech are defamatory or condemning. A person with mental illness is labeled with pejorative terms, such as "freak," "loon," "hysterical." The labels are usually metaphors, the original meaning of which is given little thought by many (Goffman
1963). As members of society have internalized these phrases into everyday communication as part of the socialization process, they are unaware of the fact that they reproduce the stereotyped image of mental illness, which leads to the marginalization of concerned people.

Therefore, in addition to the problems that impairment causes to individuals, it is necessary to study disabling social mechanisms. At the same time, the factual nature of the impairment cannot be ignored and the whole problem cannot be viewed only on the social level. Regardless of discriminatory labeling practices, the consequences of impairment often make it impossible for individuals to fully participate in many social activities. As Goodley states (2017:85 [original emphasis]), "impairment is a predicament and can be tragic." Disability is, therefore, "produced as much by environmental and social factors as it is by bodily conditions" (Adams, Reiss, and Serlinet 2015:5). Thus, in the case of mental illness, an individual's specific behavior reflects not only their illness but also how their social environment perceives them through the stereotypical view of mental illness.

In this context, the diagnosis of mental illness must, therefore, be seen not only as an individual disease but also as a social label that contributes to individual social marginalization. Diagnosis is not only a neutral description of the disease but also a prescription for how an individual should behave and be treated by society. "[I]t seems politically naive to suggest that the term 'impairment' is value-neutral, that is, 'merely descriptive,' as if there could ever be a description that was not also a prescription for the formulation of the object (person, practice, or thing) to which it is claimed to innocently refer" (Tremain 2001:621 [original emphasis]). Disability is a label 
that is imposed on an individual, and the individual gradually internalizes it, often not able to distinguish the societal disabling mechanisms from the effects of impairment.

Thus, while it is necessary to distinguish impairment and disability on a practical level, and to be aware of the sociocultural dimension of marginalization of individuals with impairment, in fact, these two entities form a whole wherein the factual state of impairment cannot be separated from how the individuals with impairment are viewed by society and how they internalize that view themselves. "From a critical and deconstructive point of view, impairment is no longer conceptualized as a distinct sign, neither a natural nor a cultural one" (Schlegel 2017:107). Moreover, the individual is marginalized and excluded through one's label by the dominant discourses of the majority and its institutions, but, at the same time, the individuals themselves accept and reproduce their label not only concerning themselves but also in relation to the other labeled individuals and the majority. The individual's disability is not only produced by the dominant discourse but they often reproduce it themselves through their activities when they accept their inferior position in society (Foucault 1985; Tremain 2006). In this way, both disability and (often) impairment, both society and (often) the disabled individuals themselves partake in the process of marginalization.

\section{Labeling}

The personality of individuals with mental illness is socially constructed as deviant in the sense that the individuals are often perceived as persons unpredictably violating social norms. This unpredictability may stem, in part, from the nature of their illness (from their impairment), but, based on the impair- ment, individuals get a social label, a group identity of the deviant (which is a disability).

When individuals violate the group's norms, they trigger a social reaction (Lemert 1951). It is rare for one act to provoke such a strong reaction as directly identifying the perpetrator as deviant, and so the individual has the option to rationalize their behavior-this is the primary phase of deviance. Once the individual no longer wants to or can rationalize their behavior, they reach the secondary deviance phase. The individual is not only stigmatized by the majority; they also gradually begin to identify themselves with the label. When the deviant role is accepted and adopted, an integrating process comes into play, in which the individual also begins to identify with other roles arising from the main deviant role. The "adjusted" deviant is, in short, an individual who accepts their deviant "social status, role, and self-definition" (Lemert 1951:96).

Lemert also sought to find the answer to what makes a person stop rationalizing their actions and embrace their deviant role. He identified two main reasons. The first is that it is exhausting to be constantly struggling with the social definition of one's self (with the label), to be forced to always present adequate reasons for one's behavior perceived as deviant. The other reason is joining an existing "deviant social organization" with a value system the person may identify with and thus enjoy the group solidarity (Lemert 1951). In the case of this study, the deviant social organization could be the participant's family or the client center for people with mental illness that they visit.

Becker (1966) calls this process a "deviant career." $\mathrm{He}$, like Lemert, claims that there are sequences of events that occur when norms are broken, which 
can lead a person to adopt a deviant personality as their own. The concept of the deviant career refers to a person's shift from a position in a "normal" social system to a "deviant" one. One of the most important steps in building a stable pattern of deviant behavior is the experience of having been publicly labeled "deviant," which leads to the change of the individual's public identity, due to which the individual is suddenly seen as someone else than whom they had been considered to be until now-suddenly the individual is, for example, a "schizophrenic." Having a deviant characteristic may create a symbolic value, thanks to which the individual is automatically expected to have undesirable characteristics associated with the deviant label-people labeled as "schizophrenic" are, for example, seen as unreliable and unexpectedly aggressive.

Treated as deviant by society, the individual is confronted with a self-fulfilling prophecy-a set of mechanisms is developed, shaping the individual into the form attributed to him or her by others. The individual is excluded from participation in "conventional community," and they finally join an "organized deviant group" (Becker 1966; also see Lemert's [1951] "deviant social organization"). This has a major impact on the self-concept of the individual. They begin using the language of the deviant group and expressing their motives with phrases learned from interaction with other people labeled as deviant. As these people face identical problems owing to social rejection, being a member of an "organized and institutionalized deviant group" only strengthens their deviant identity. Organized groups serve to teach people with a deviant label how to anticipate problems when they break rules and how to rationalize the fact that they have not stopped their "deviant" activities (Becker 1966). Although the client center that research participants attend is intend- ed to help these people to cope with their illness, it is often a place where they confirm their differences, reinforcing their separation from the majority.

A very effective way of segregating an individual into an organized deviant group and deviant label is to block them from assuming a non-deviant role. For example, former psychiatric patients have problems securing a job even if their behavior is acceptable, as the research showed. This shows that the rejection of people with mental illness is a deeper manifestation of stigmatization rather than an assessment of actual behavior (Scheff 1999). Even if discharged patients no longer have any symptoms and could regain full social and economic competencies, they continue to be closely monitored by others who consider them suspicious. An ordinary mistake or conflict is dramatized as the relapse of incurable mental illness (Lemert 1951).

\section{Certainty from Uncertain Diagnosis}

In psychiatry, a medical diagnosis-as uncertain as it often is-can irreversibly change the patient's status (Scheff 1999). Using the terminology and approach of mad studies (see, e.g., Menzies, LeFrançois, and Reaume 2013), Wilson and Beresford (2002) call themselves "psychiatric system survivors." They joined the movement of mental health service users, criticizing the symbolic violence manifested in the power held by medical discourse over the formation of a patient's identity.

Generally, the psychiatric community views mental illnesses as being similar to physical illnessesthey have their origin in an individual and can be identified with the help of an expert (Kutchins and Kirk 1999). However, mental illnesses cannot be established using a laboratory test, which is acknowl- 
edged by an increasing number of psychiatrists. "We will never have a biomedical science that is similar to hepatology or respiratory medicine, not because we are bad doctors, but because the issues we deal with are of a different nature" (Bracken et al. 2012:433). The patient's problems are context-dependent, and treatment cannot be successful if it does not take into account the relationships and values shared by both the patient and the society in which the patient lives (Bracken et al. 2012). Mental illness is not just an impairment treatable by means of pharmacology, but its manifestations are also created by the disabling mechanisms of society.

In the traditional psychiatric model, built on the model of other medical disciplines, the patient is not seen as a specific personality, but as a representative of the diagnosis assigned to them by the psychiatric system, often based on subjective assessment of psychiatrists, leaning on symptom descriptions published in diagnostic manuals (Wilson and Beresford 2002) - see also the situation described by the research participants: their diagnosis has been changed several times in their lifetime. Based on this diagnosis, society gives an individual the label of mentally ill. The individual is placed by this label in a category around which society often acts in a way that is discriminatory in many respects (Becker 1966; Waldschmidt 2017). The individual is then no longer a unique individual having a particular disease, but a personification of the disease itself. They no longer suffer from, for example, schizophrenia, but they are schizophrenic, or just "crazy" and "insane." Patients themselves often internalize this attitude and are unable to verbalize their experiences without using the concepts of experts and describe their mental states using medical terminology - this is how many research participants referred to each other within the client center. Thus, they reproduce the privileged position of medical discourse over the categorization of highly individual states and feelings of patients. This can have, among other things, a negative economic impact on them, when psychiatrists warn their patients that they will probably not be able to do stressful work, if they can work at all, and thus make "second class citizens" from them (Wilson and Beresford 2002).

\section{Research Findings}

\section{Family and Partner Relationships}

In the context of mental illness, family plays a pivotal role, as was evident from how frequently the interviewees discussed the issue at hand. Family members are often swayed by prejudice until they gain first-hand experience with mental illness (Thornicroft 2006). All interviewees reported someone in the family who had no understanding of their mental illness. The interviewees were criticized for being too lazy and inefficient, and for making their family ashamed of them. Apart from this, they were treated with exaggerated care, which humiliated them as it portrayed them as being incompetent.

The interviewees coped with these reactions in several ways. Some said they finally separated themselves from their family. Almost half of the interviewees confirmed that one of their family members had suffered from mental illness and that this had affected how the family responded to their illness. As a result, these people were met with greater understanding in their family than those whose families had no experience with mental illness. In that case, however, it happened that the family as a whole was labeled "mentally ill" and was marginalized by society as an organized deviant group (Berger 1966). 
Amelia described an utter lack of understanding by her family wherein the members of the family did not believe she was mentally ill: “Well, they don't want to admit it, my mental health disorder...I've also been treated for a thyroid disorder. And so they're always asking me about my thyroid, but never ask how I'm doing mentally. They say it's not a condition at all." Thus, her family does not accept her impairment, which is disabling as a result. Amelia's family tries to rationalize her rule-breaking behavior, attributing it to a socially acceptable health disorder, to prevent her from being labeled as mentally ill. One of the reasons is that Amelia's family fears that her mental illness would harm the public identity of the whole family. Families like Amelia's may fear the label and stigma to such an extent that they try to discourage the relative with an illness from receiving psychiatric treatment (Praško et al. 2012). The family worries that once a member is diagnosed as mentally abnormal, the entire family will be labeled. Goffman (1963) refers to such a transfer of stigma from a labeled individual to their family as "courtesy stigma."

Family members can make an individual's mental condition worse not only by passively ignoring his or her impairment, but can also actively deepen the negative conditions associated with impairment. Hugo was talking about his mother, who had been a strict parent and remained so even dozens of years later, long after Hugo fell ill: "if I suffered an episode, mom would just scold me. Which makes things even worse, 'cause getting all stressed doesn't do me any good." When someone in the family develops psychotic symptoms, the family usually finds it very difficult to understand what is happening, which may cause their inappropriate reactions only to aggravate the condition (Thornicroft 2006). In this case, Hugo's mother is disabling him by amplifying his mental condition. The approach of Hugo and Amelia's families makes them marginalized in their families, and therefore they seek support elsewhere (often in the client center), thus separating themselves from their families.

Elisabeth's family is, on the contrary, an example of the organized deviant group. Elisabeth believes her disorder is partly inherited: "In my family, it's my granny, mom, a cousin, another cousin, an uncle who have suffered from depression...And my family, they took it really well because they've been through it." Her family not only views Elisabeth in a non-discriminatory way, but they are also able, thanks to their experiences, to help Elisabeth when the illness presents itself: "I can't really tell when I'm already on the way. People around me are better at this...Mom just warns me, 'Hey, Betty, you're getting manic.' And I can see she's right, and I didn't use to be able to see that." On the other hand, Elisabeth thinks her mother is too worried: "She's always checking on me...I know that she does that because she loves me, but I'm 40 and I still have to call her every morning and evening. I just think it's way over the top." Thus, the mother's approach to Elizabeth can be seen not only as helping but, at the same time, as disabling. Moreover, many of Elisabeth's relatives had experiences with psychiatric treatment, labeling, and social stigma. By embracing the social status they received due to the label, they helped Elisabeth accept it, as well. In this way, the family deepens her separation from the majority.

In some cases, the interviewees believed that their psychiatric diagnosis improved their quality of life and relations with others. This is the case of Susan, who had mental problems before, but was diagnosed with mental illness only when she was 
40 years old. She and her siblings had a very strict upbringing. When she felt sick and had trouble getting out of bed, her mother was angry at her for being lazy and sometimes gave her a beating. Susan herself was not sure what was wrong with her. Not much attention was paid to those things back then, and so no one thought to seek professional help. She attempted suicide when she was 18 years old. She was not properly examined then either: "I was interviewed by a psychiatrist as to why I had done it, and she said: 'That was a silly thing to do, wasn't it?' And I replied: 'Yeah, it was.' And that was it."

Susan has been ill for a long time without knowing it, and she found it difficult to cope with her mood swings. When she was diagnosed and began to receive treatment, she felt a great relief: "I was happy to finally know what was wrong with me... And also, the moment I got medication, everything fell in its place for me, just the way it should be." In addition, Susan appreciated her diagnosis for improving her relationship with her eldest son, whom she thought had suffered from her extreme mood swings: “That's, I'd say, the greatest benefit that I was able to talk about it... and managed to explain what's wrong with me." In Susan's case, the relatives who had no previous experiences with mental illness did not understand her situation and tended to reject her. However, her son, when he got the information, supported her and, today, she babysits his children. Thus, the diagnosis itself and its treatment, if not accompanied by stigmatizing social reactions, can help the individual. Nevertheless, Susan fears negative social reactions outside her primary family. She does not even include her current partner in her family, and therefore she is unwilling to discuss her mental problems with him. While he knows she is on medication, he is unaware of the true reason. Susan does not spend much time with him, and she referred to him as a "stranger," saying that "I do not disclose my condition to strangers." She tries to spend a lot of time on her own because she is unsure how he would handle the information: "Sometimes I sleep for a day when I am not well...I'm not sure whether my partner would put up with something like that if he saw me like this." Susan's case demonstrates that diagnosis may help eliminate troubles; impairment, if not seen as impairment and if not treated as such, may be a real burden for fulfilling life. On the other hand, she tries to hide her diagnosis from some people to avoid the mentally ill label, and she often segregates herself from other people, even her partner, to avoid negative reactions.

\section{Neighbors and Friends}

One's hospitalization in a psychiatric ward is likely to become known to members of the local community. They may view the hospitalized through the label associated with psychiatric treatment and thus contribute to their exclusion from the majority. Every interviewee has faced prejudice; some of them mentioned in this context their neighbors. Elisabeth reminisces: "I was hanging up the laundry, and she said something along the lines of, 'Why don't you go back to the madhouse, where you belong.'... Neighbors look at me differently now. I think they talk about me as the 'loony Beth.'” This is a way people with deviant labels are symbolically excluded within their social environment.

The interviewees strove to "look normal" when dealing with people outside their family who are considered mentally healthy. In the case of people with mental illness, trivial failures are seen as direct evidence of their difference. The labeled are aware of it and conform their behavior to it. For example, when talking to "normal" people, the stigmatized 
individual has to carefully choose every word (Goffman 1963). This can lead to withdrawal from society, as was the case with Susan: "And I never try to make small talk...I tend to keep out of sight. So as not to give a reason or something. I'm worried about it, don't wanna be made fun of or something, don't wanna say the wrong thing."

Having to constantly check oneself requires a lot of energy (Lemert 1951), so the majority of the interviewees withdraw from social life and form relationships mostly within a deviant social organization made up of individuals sharing the mental illness label. Most of the interviewees conferred that mental illness had completely changed their lives-their priorities changed, they started to see different people. This transformation of the labeled individual is a typical example of a deviant career. It involves isolation from a conventional community, followed by the decision to join an organized deviant group (Becker 1966), the client center in the case of the research participants. This is where labeled individuals meet people facing very similar problems, who are empathetic to them, and thus they mutually reinforce their "deviant" identities. Many interviewees describe joining the center as a "new beginning." They were able to make friends there, to whom they did not need to explain how they felt or apologize for their behavior. The fact that the clients felt fully accepted in the group has led many of them to withdraw from the conventional community to the point that they have no other friends than those with mental illness.

For example, Helen made her first closer friend at the age of 18, but the friend ended their friendship after learning about Helen's time in the psychiatric ward: "She thought I was a loon...She stopped talking to me 'cause of my illness." Later, Helen made a new friend. Helen was not having any symptoms, and when she decided to confide in her friend, the friend did not judge her for her mental illness: "she was fantastic, took it really well. Also, because she knew me when I was doing well." However, when Helen was hospitalized again, and she called her friend, she felt the friend was not happy to hear from her. Today, Helen no longer tries to make friends outside the client center, where she has found people who understand: "I don't try to find friends among the healthy crowd anymore. You can be yourself here [in the center]."

Helen's case illustrates secondary deviance (Lemert 1951), characterized by gradual identification with the label given by society and by the adoption of the resulting role. This is manifested by isolation from the majority and by a focus on relationships within deviant social groups, which hold values and norms different from those prevailing in social groups considered normal. Helen's view was echoed by the vast majority of the interviewees, such as Sylvia: "I've made good friends [in the center] who make me happy...I just don't hang out much with healthy people 'cause they live different lives." In addition, some of the interviewees have met their partners in the center, for example, Helen and James: "Mental illness gave me Helen...I don't think I'd be able to, since I'm sick, to have a healthy partner. Things are awesome between us like this. I mean, we're just very much alike."

\section{Work Experience}

Work plays a pivotal role in one's mental health. It offers the opportunity to gain skills, money, social contacts, and it can become a source of a valued social position and identity. The absence of employment is often connected with exclusion from society. 
Although those with psychological problems may greatly benefit from employment, diagnosis is one of the most effective ways to disqualify them from the job (Thornicroft 2006). This is why employment was a much-discussed issue for the interviewees.

Although none of the research participants worked full-time at the time of the interviews, work is an important factor for many of them, not only financially but also socially. Employment would make them part of the majority and earn them a non-degrading social status. For many of the interviewees, "being normal" means working, but illness and medication make them too tired for "normal" work. That is why most of them claim benefits providing financial support to those unable to make a living because of their impairment.

Employing people with an impairment is financially supported by the state, so employers create protected jobs for them. However, although they promise a protected environment to their employees, many interviewees have never been given such benefits. For example, Melissa and another client from the center took a protected job in a museum café. The other people working in the café first kept their distance, but it disappeared over time, which was not always an advantage: "Once they saw...that we could manage, they...wanted us to give $100 \%$ at work." Finally, Melissa had to quit because the job proved too demanding. Helen worked for an IT business, which employed people on impairment benefits, but failed to provide them with sufficient working conditions: "I was made to work just like the healthy people...All I can say is that it's a business that hires the impaired. And it's not taken into account at all." Therefore, Helen had to leave the job. This shows that although the label makes life difficult in many situations, disregarding the im- pairment, which is a life complication in itself, is not a solution; the disregard can disable the individual.

Helen also worked as an administrative assistant in a law firm, where all employees knew they would be helped by clients of a mental health center. The clients, on the other hand, knew nothing about their co-workers: "That was a real handicap...Some of the staff made direct fun of us and things like that." Therefore, Helen quit the job since working there was not the way to overcome her impairment; on the contrary, the labeling environment strengthened her disability.

Multiple interviewees also reported that people labeled as mentally ill would be denied some of the jobs designed for individuals with impairment. This experience was reported, for example, by Bonnie: "I told them I had a mental condition. 'Mental, you say? I'm sorry."' Elisabeth shared a similar story: "And he asked me why I was claiming [impairment benefits], and then he never called again." The interviews showed that research participants were discriminated against due to their mentally ill label even when applying for jobs that were publicly promoted as protected.

Former psychiatric patients struggle to find a job even if their behavior is acceptable. Although the symptoms of the disease are eliminated, they are mistrusted by potential employers. Therefore, most of the interviewees said they would conceal their illness from their employers to avoid dismissal or rejection. One of them is Janine, talking about her job in a hotel. She was hired by a woman who knew her, but did not precisely know about her condition: "Well, she found out later and got really upset with me, and she said I should've told her...I told her I'd not done it because I'd thought she wouldn't 
have hired me. And she said: 'Yeah, you're right, I wouldn't have hired you."'

\section{Impairment Benefits-Aid or Disadvantage?}

Claiming impairment benefits is a complication for some of the interviewees. There are conditions they are required to meet to be able to claim the benefits, and so they worry that they could lose this stable income if they find a job. This is described by Thornicroft (2006), who focuses on the causes that prevent people with mental illness from joining the workforce. One of them is the effects of social welfare payments. For many people with health impairment, these are the only reliable sources of income. Mental health service users are thus not willing to surrender this financial security because they fear they could soon lose the new job. This is why they often do not even seek jobs and stay separated from the majority.

This is the case of Janine, who had only a few parttime jobs but no permanent employment since she was diagnosed with mental illness. Ironically enough, she believes she would benefit from having a regular job: "I'm home all day long. It'd help if I went to work and had to get up, have a routine." Although Janine would like to work, she is not seeking any employment: "It's all limited by the fact that if you've a pension and fix yourself with a job, you could lose it." In short, impairment benefits help those who are unable to work at full capacity, and yet they also serve to segregate individuals into a deviant label.

Many of the interviewees find a solution to their work-related problems in the client center. It provides them with simple job positions (receptionist, cleaning staff, etc.) without putting pressure on performance. As Janine says: “Well, it's only the center who don't mind when...you don't cope well with stressful situations." These are often unpaid positions, and yet they are popular with the interviewees. Phillip was paid for cleaning in the center "about a year and a half," and then, as he said, "I had to decide whether I'd go on cleaning the place and not be a client or be a client and not do the cleaning. When I had to make a choice, for me, it's more important to hang with the people here than make money."

The demand for employment at the mental health center supports Lemert's (1951) concept of secondary deviation, where the individual with the deviant label is rejected by the majority and isolated. The isolation is further reinforced by employment in an environment filled with people stamped with the same label of the mentally ill. In line with Becker's (1966) theory, not only did these individuals enter an organized deviant group, separated from the conventional community, and made friends there, they also found jobs there thanks to the support the group provides, which further strengthened their deviant identity. Preventing the individual from entering a non-deviant role, namely, a standard job, is an effective tool used to segregate the individual with mental illness into the deviant label (Scheff 1999), which is embraced by multiple interviewees.

\section{Conclusion}

The research suggested that family played an important role in the lives of the research participants. Some of the interviewees were helped by their families. It was the case of the families which had experience with mental illness and had gone through the same labeling process and social stigmatization 
as the participants. In these cases, the family has itself become an organized deviant group which, in fact, enhances the individual's isolation from the majority. Some others were given degrading labels by their relatives, who treated them as inferior or felt ashamed of them in their worry of receiving "courtesy stigma" as a whole (Goffman 1963), or were overly concerned to a degree that made them appear incompetent. Research participants were also rejected by their neighbors, former friends, and in the working environments outside the client center-they were discriminated against in the field of work even when applying for positions designated for disadvantaged people.

People labeled mentally ill often prefer minimal contact with their families, neighbors, and former friends; they do not have regular jobs and seek support in a different environment. Thus, in a way, they exclude themselves from the majority, finding a solution to their problems in the client center that, as a result, functions as an organized deviant group. The entrance to the center is a "new beginning" for them that may lead to almost complete withdrawal from the majority. They have friends there; some of them even found their partners there. They can also work there, free from pressure from the employer about their performance. However, the positions are often unpaid and isolated from the majority, so they are, in fact, a part of work segregation.

Therefore, the interviewees agreed that mental illness had completely changed their lives. The label changed their identity as they were suddenly viewed as a different person, an "outsider" (Becker 1966). Their illness and label made them become interested in other things and see new people dealing with the same problems as theirs, not due to shared impairment (their diagnoses are different and change over time) but because the "mad" label leads to similar afflictions (Kolářová 2012). They empathize with one another, mutually reinforcing their "deviant" identity.

The disabling label "mentally ill" can cause more harm than impairment because it creates an idea of how the labeled behave and what their place in society is. Society tends to see people with mental illness as the personification of a diagnosis/label, which affects their self-concept. People with mental illness internalize the degrading view of society and lack the ability to face the stigmatizing label and its effects. Their problems are thus largely caused by the social attitudes that these people face and which medicine is often not able to take into account in its treatment procedures. Without changes in social attitudes towards people with mental illness, their condition and situation cannot improve. Psychiatry needs to cooperate more with the social sciences because without such cooperation it cannot help these people enough. It is necessary, using the theoretical approaches and methodology of the social sciences, to study the attitudes of society and "be more open to the experiences of patients" (Uchtenhagen 2008:538); not only to rely on "the words of those who tried to cure, tame, correct, or end it," but also focus on "a rich and self-conscious record of the perspectives of disabled people themselves" (Adams et al. 2015:9), which was the attempt of this study.

Psychiatrists, no matter how good they might be as diagnosticians and with the best medical tools at hand, cannot change the disabling attitude of a patient's social environment from the position, which is built on the biological model of the disease and the pharmaceutical paradigm of treatment. This model is not able to take into account that some of the symp- 
toms may not be caused by the disease itself, or only by this disease, but are also caused by social attitudes. The psychiatrist then treats the cause (impairment), but until the consequences caused by society (disability) are eliminated, the treatment cannot be successful. And so, even in the framework of psychiatry, "there is a growing appreciation that personally meaningful recovery from a serious mental disorder is not necessarily related to the specific treatments that are prescribed" (Bracken et al. 2012:432).

Psychiatric approaches based primarily on the biomedical model of disability should be replaced by a model that takes into account the socio-psychological dimension of the disease, in which "in the words of its founder Engel...'all three levels, biological, psychological, and social, must be taken into account in every health care task.' No single illness, patient, or condition can be reduced to any one aspect" (Ghaemi 2009:3).

\section{References}

Adams, Rachel, Benjamin Reiss, and David Serlinet. 2015. "Disability." Pp. 5-11 in Keywords for Disability Studies, edited by R. Adams, B. Reiss, and D. Serlinet. New York: New York University Press.

Becker, Howard. 1966. Outsiders. Studies in the Sociology of Deviance. New York: Free Press.

Bracken, Pat et al. 2012. "Psychiatry Beyond the Current Paradigm." British Journal of Psychiatry 201(6):430-434.

Foucault, Michel. 1985. "Power, Sovereignty, and Discipline." Pp. 306-313 in States and Societies, edited by D. Held et al. Oxford: Blackwell.
This is a model that is "more scientific (since it includes also psychosocial sciences), pragmatic, and humanistic" (Ghaemi 2009:3). It offers a new approach in the form of "social psychiatry," which focuses on "keeping the emotionally and mentally ill in the community, or at least attempting social reintegration wherever possible...enabling the individual to live adequately in a normal social context" (Uchtenhagen 2008:535). And this cannot be successful without the education of a society focused on removing negative labels and prejudices that are stereotypically associated with mental illness.

\section{Acknowledgment}

The study was written with the support of the Czech Ministry of Education, Youth and Sports, grant project IGA_FF_2018_023 (Social Sciences 2018).

Ghaemi, S. Nassir. 2009. "The Rise and Fall of the Biopsychosocial Model." The British Journal of Psychiatry 195(1):3-4.

Goffman, Erving. 1963. Stigma: Notes on the Management of Spoiled Identity. Englewood Cliffs, NJ: Prentice-Hall.

Goodley, Dan. 2017. "Dis/Entangling Critical Disability Studies." Pp. 81-97 in Culture-Theory-Disability: Encounters between Disability Studies and Cultural Studies, edited by A. Waldschmidt, H. Berressem, and M. Ingwersenet. Bielefeld: Transcript Verlag.

Kaufmann, Jean-Claude. 1996. L'entretien compréhensif [Comprehansive Interview]. Paris: Nathan. 
Kolářová, Kateřina, ed. 2012. Jinakost, postižení, kritika. Společenské konstrukty nezpusobilosti a hendikepu [Otherness, Disability, Criticism. Social Constructs of Impairment and Disability]. Prague: Slon.

Kutchins, Herb and Stuart A. Kirk. 1999. Making Us Crazy. London: Constable.

Lemert, Edwin M. 1951. Social Pathology: A Systematic Approach to the Theory of Sociopathic Behavior. New York: McGraw-Hill.

Menzies, Robert, Brenda A. LeFrançois, and Geoffrey Reaume. 2013. "Introducing Mad Studies." Pp. 1-22 in Mad Matters: A Critical Reader in Canadian Mad Studies, edited by B. A. LeFrançois, R. Menzies, and G. Reaume. Toronto: Canadian Scholars' Press.

Praško, Ján et al. 2012. "Stigmatizace a panická porucha [Stigmatization and Panic Disorder].” Psychiatrie pro praxi 13(3):100-103.

Scheff, Thomas J. 1999. Being Mentally Ill. A Sociological Theory. 3rd ed. New Brunswick, London: Aldine Transaction.

Schlegel, Rouven. 2017. “Beyond Judgment: Towards Critical Disability Studies." Pp. 103-110 in Culture-Theory-Disability: Encounters between Disability Studies and Cultural Studies, edited by A. Waldschmidt, H. Berressem, and M. Ingwersenet. Bielefeld: Transcript Verlag.
Thornicroft, Graham. 2006. Shunned: Discrimination against People with Mental Illness. Oxford: Oxford University Press.

Tremain, Shelley. 2001. "On the Government of Disability." Social Theory and Practice 27(4):617-636.

Tremain, Shelley. 2006. "Foucault and the Government of Disability." Scandinavian Journal of Disability Research 8(1):75-77.

Uchtenhagen, Ambros A. 2008. “Which Future for Social Psychiatry?" International Review of Psychiatry 20(6):535-539.

UPIAS. 1976. Fundamental Principles of Disability. London: Union of the Physically Impaired Against Segregation.

Waldschmidt, Anne. 2017. "Disability Goes Cultural: The Cultural Model of Disability as an Analytical Tool." Pp. 1927 in Culture-Theory-Disability: Encounters between Disability Studies and Cultural Studies, edited by A. Waldschmidt, H. Berressem, and M. Ingwersenet. Bielefeld: Transcript Verlag.

Wilson, Ann and Peter Beresford. 2002. "Madness, Distress, and Postmodernity: Putting the Record Straight." Pp. 143-158 in Disability/Postmodernity: Embodying Disability Theory, edited by M. Corker and T. Shakespeare. London: Continuum.

\section{Citation}

Maloušková, Kateřina and Martin Fafejta. 2021. “The Social Marginalization of People Living with a Mentally Ill Label-Family, Friends, and Work." Qualitative Sociology Review 17(3):76-89. Retrieved Month, Year (http://www.qualitativesociologyreview.org/ ENG/archive_eng.php). DOI: https://doi.org/10.18778/1733-8077.17.3.04 